\title{
Deposição de serrapilheira e variáveis qualitativas da produção de biomassa anual em sistemas de vegetação de caatinga e sistema agroflorestal no município de Cocal-PI
}

\section{Deposition of hills and qualitative variables of the annual biomass production in systems of caatinga and agro-forestry system in the Cocal-PI}

\author{
Raíza da Silva Lima ${ }^{1}$, John Kenedy da Silva Fontenele ${ }^{2}$, Vandenberg Lira Silva ${ }^{3}$, Janailton \\ Martins Chaves ${ }^{4}$, Jean Herllington Araújo Monteiro ${ }^{5}$
}

DOI: https://doi.org/10.52719/bjas.v3i1.3944

\section{RESUMO}

A serrapilheira é fundamental para produção de matéria orgânica, sendo importante para manter a cobertura e umidade do solo, protegendo-o e promovendo a sustentabilidade da área. Objetivou-se com a pesquisa estimar a produção de biomassa da serrapilheira em sistemas de Caatinga (Nativa - CN; Antropizada - CA; e, Degradada - CD) e Sistemas Agroflorestais (SAF) seguindo o delineamento inteiramente casualizado em esquema fatorial $4 \mathrm{x} 2$ (quatro sistemas $\mathrm{x}$ dois períodos). A produção de serrapilheira acima do solo foi coletada mensalmente, durante o ano de 2018, utilizando-se um quadrado de $0,25 \mathrm{~m}^{2}$ sendo o material posteriormente armazenado e levado ao laboratório. Foram analisadas as variáveis: biomassa de folhas verdes $\left(\mathrm{BFV}, \mathrm{kg} \mathrm{ha}^{-1}\right.$ ), biomassa de estrato lenhoso (BLEN; $\mathrm{kg} \mathrm{ha}^{-1}$ ), biomassa de estrato herbáceo (BHB; $\mathrm{kg} \mathrm{ha}^{-1}$ ), Biomassa de forragem Total (BFT, $\left.\mathrm{kg} \mathrm{ha}^{-1}\right)$. Observou-se que na época seca os sistemas CA $\left(7.041,00 \mathrm{~kg} \mathrm{ha}^{-1}\right)$ e SAF $\left(7.658,10 \mathrm{~kg} \mathrm{ha}^{-1}\right)$ apresentaram maior deposição de serrapilheira. Na época chuvosa houve maior produção de serrapilheira na CA $(7.483,00 \mathrm{~kg} \mathrm{ha}$ $\left.{ }^{1}\right)$ e $\mathrm{CN}\left(5.595,23 \mathrm{~kg} \mathrm{ha}^{-1}\right)$. A CN $\left(5.256,27 \mathrm{~kg} \mathrm{ha}^{-1}\right)$ e CA $\left(7.176,80 \mathrm{~kg} \mathrm{ha}^{-1}\right)$ apresentam a deposição de serrapilheira com maior quantidade do componente biomassa de folhas verdes (BFV) na época chuvosa. O sistema CD apresentou apenas BFV $\left(1.181,37 \mathrm{~kg} \mathrm{ha}^{-1}\right)$ como componente da serrapilheira durante todo o ano. A BFV foi a que contribuiu com maior percentual na composição da serrapilheira em todos os sistemas avaliados. A CN e SAF apresentaram produção de biomassa elevada o ano inteiro, com importância principalmente para o período seco.

Palavras-chave: Clima. Vegetação decídua. Vegetação nativa.

\section{ABSTRACT}

Litter is essential for the organic matter production, important for maintaining soil coverage and moisture, protecting and promoting the sustainability of the area. The objective of this research was to estimate the biomass production of litter in Caatinga systems (Native - NC;

\footnotetext{
${ }^{1}$ Instituto Federal do Piauí - Campus Cocal

2 Instituto Federal do Piauí - Campus Cocal

${ }^{3}$ Instituto Federal do Piauí - Campus Cocal

${ }^{4}$ Instituto Federal do Piauí - Campus Cocal

${ }^{5}$ Instituto Federal do Piauí - Campus Cocal
} 
Anthropized - AC; and, Degraded - DC) and Agroforestry Systems (AFS) following a completely randomized design in a $4 \times 2$ factorial scheme (four systems $\mathrm{x}$ two periods). Litter production stored on the soil was collected monthly, during 2018 , using a square of $0.25 \mathrm{~m}^{2}$ the material being later stored and taken to the laboratory. The following variables were analyzed: green leaf biomass (BFV, $\mathrm{kg} \mathrm{ha}^{-1}$ ), woody stratum biomass (BLEN; $\mathrm{kg} \mathrm{ha}^{-1}$ ), herbaceous stratum biomass (BHB; $\mathrm{kg} \mathrm{ha}^{-1}$ ), Total forage biomass (BFT, $\mathrm{kg} \mathrm{ha}^{-1}$ ). It was observed that in the dry season the AC $\left(7,041.00 \mathrm{~kg} \mathrm{ha}^{-1}\right)$ and AFS $\left(7,658.10 \mathrm{~kg} \mathrm{ha}^{-1}\right)$ systems showed higher litter deposition. In the rainy season, was observed higher litter production in AC $(7,483.00 \mathrm{~kg}$ $\left.\mathrm{ha}^{-1}\right)$ and NC (5,595.23 kg ha-1). NC (5,256.27 kg ha-1) and AC $\left(7,176.80 \mathrm{~kg} \mathrm{ha}^{-1}\right)$ presented litter deposition with a higher amount of the green leaf biomass (GLB) component in the rainy season. The DC system presented only GLB $\left(1,181.37 \mathrm{~kg} \mathrm{ha}^{-1}\right)$ as a component of litter during the whole year. GLB contributed the highest percentage in the composition of litter in all evaluated systems. NC and AFS presented high biomass production throughout the year, being important mainly for the dry period.

Keywords: Climate. Deciduous vegetation. Native vegetation.

\section{INTRODUÇÃO}

O bioma Caatinga compreende um tipo de vegetação que cobre a maior parte do semiárido brasileiro apresentando diversidade de conjuntos florísticos, cujas distribuições são determinadas, em grande parte, pelo clima, relevo e embasamento geológico que, em suas múltiplas interrelações, resultam em ambientes ecológicos bastante distintos. A Caatinga é um bioma brasileiro muito explorado nos dias atuais, pela sua fonte de energia, sendo a madeira o principal recurso explorado, o que pode degradar cada vez mais essa região semiárida (Henriques et al., 2016), ao passo que grande parte de seus ecossistemas originais já foram antropizados influenciando a distribuição, a riqueza e a diversidade dessas espécies vegetais (Araújo, 2013).

De acordo com Henriques et al. (2016), a vegetação da Caatinga apresenta, em sua maioria, espécies caducifólias que perdem toda ou parcialmente a folhagem como mecanismo fisiológico de adaptação aos períodos prolongados de estiagem e déficit hídrico no solo. Essa deposição de material orgânico na superfície do solo promove a formação de uma camada de resíduos denominada serrapilheira, que vai ser decomposta pelos organismos do solo, sendo de grande importância para a ciclagem de nutrientes e a manutenção da umidade e atividade biológica da área.

A serrapilheira é fundamental para manter a umidade no solo por meio da sua cobertura, o protegendo dos raios solares e da erosão causada pelas primeiras chuvas; promovendo assim a redução dos níveis de degradação da área e, nessa perspectiva, o estudo sobre a produção serrapilheira torna-se fundamental a compreensão dos fatores envolvidos, tidos como fatores 

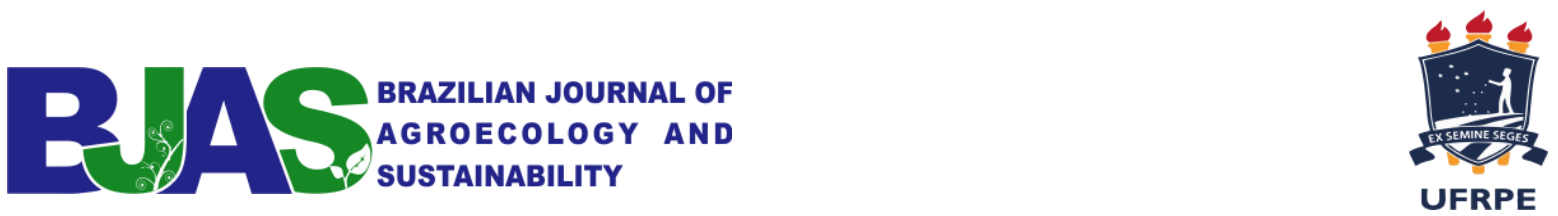

bióticos e abióticos. Nesse sentido, Silva et al. (2016) verificaram que a deposição de serapilheira é influenciada por diversos fatores, como precipitação, temperatura, vento, conteúdo de água disponível no solo, umidade do ar — tornando-se difícil quantificar a contribuição desses fatores de forma isolada, e, principalmente, correlacioná-los com a produção de serapilheira.

A serrapilheira é formada principalmente por vegetais de características decíduas como folhas, gravetos, sementes, flores, cascas e galhos componentes importantes, pois formam uma camada de proteção para o solo impedindo a compactação e permitindo aração (Souto et al., 2013). Além disso, a serrapilheira protege o solo dos intensos raios solares na época seca, e nas primeiras chuvas a proteção se volta para evitar o impacto direto das gotas das chuvas (Souto et al., 2013).

A deposição de serrapilheira sobre o solo influencia a dinâmica dos ecossistemas terrestres, seja ela de origem vegetal ou animal, existindo uma dinâmica na ciclagem biogeoquímica para os diferentes ecossistemas florestais, que proporciona melhoria nos atributos químicos e físicos do solo, acredita-se ainda que, entre as diversas tipologias florestais, existem fatores abióticos intrínsecos influenciando no processo de ciclagem dos nutrientes (Holanda et al., 2017).

Diante do exposto, e considerando a necessidade de manutenção dos ecossistemas em suas bases produtivas sustentáveis em áreas de caatinga, a compreensão da serrapilheira dentro do ciclo de produção é fundamental para a definição de tecnologias de manejo sustentáveis e pela sua contribuição com aporte de material decíduo (Corrêa et al., 2014) e ciclagem de nutrientes depositadas na serapilheira dentro do ecossistema (Silva et al., 2016). Nesse contexto, ao propor a pesquisa, o estudo possibilitou uma contribuição para o manejo e aperfeiçoamento de modelos e sistemas sustentáveis em áreas de vegetação de caatinga, a partir do conhecimento acerca da importância da serrapilheira produzida e depositada no solo.

Os sistemas agroflorestais em áreas de caatinga constituem uma modalidade de uso da terra que permite combinar simultaneamente, ou de uma maneira escalonada, cultivos agrícolas com florestas e/ou com produção animal, com o objetivo de reduzir o risco e aumentar a produtividade total e dentre as alternativas viáveis de uso da terra no bioma caatinga. Os SAFs oferecem uma produção diversificada e contínua ao longo do ano, sem degradar o solo, tornando-se um modelo agrícola promissor na aliança entre produção agrícola e conservação ambiental; e por fim, estimular a sustentabilidade ambiental nos ecossistemas, possibilitando ao agricultor uma nova perspectiva/olhar sobre os agroecossistemas produtivos. 

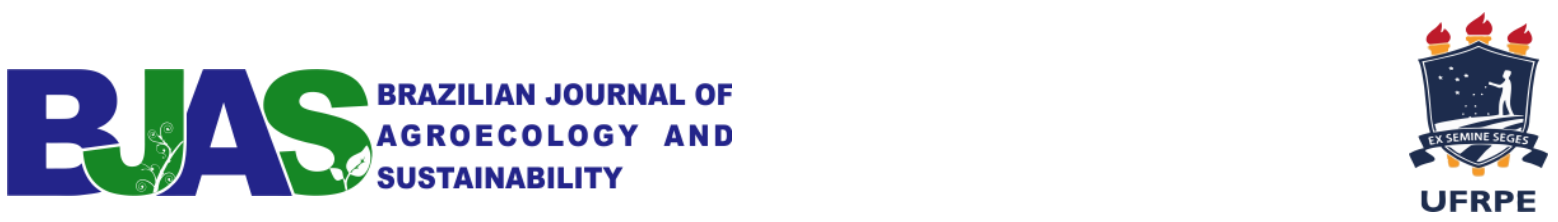

Diante disso, faz-se necessário entender a biomassa, a composição e a deposição da serrapilheira para o desenvolvimento de técnicas de manejo agroecológico e, dessa forma, o objetivo deste trabalho foi avaliar as características químicas da serrapilheira, bem como, quantificar o acúmulo/deposição de serrapilheira em sistemas de Caatinga (Nativa - CN; Antropizada - CA e Degradada - CD) e Sistemas Agroflorestais (SAF) no Município de Cocal, no Norte do Piauí.

\section{METODOLOGIA}

\subsection{Caracterização da área de estudo}

A execução da pesquisa foi conduzida na cidade de Cocal - PI, região Norte do estado do Piauí, na unidade didática de SAF - Sistema Agroflorestal pertencente ao Instituto Federal de Educação, Ciência e Tecnologia do Piauí - IFPI campus Cocal e áreas de vegetação de caatinga, compondo os sistemas de vegetação de caatinga (Nativa- $\mathrm{CN}$; Antropizada - CA; e, Degradada - CD) e Sistemas Agroflorestais (SAF). A área total da execução da pesquisa foi caracterizada por subsistemas, compostas pelo sistema agroflorestal e áreas de vegetação de caatinga, contendo distintas coberturas vegetais.

O sistema agroflorestal consistiu em uma área de 30 x $50 \mathrm{~m}$ totalizando $150 \mathrm{~m}^{2}$, uma área de vegetação de caatinga degradada, uma área de vegetação de caatinga antropizada e uma área de vegetação de caatinga nativa adjacente, representando o mesmo dimensionamento $30 \mathrm{x}$ $50 \mathrm{~m}$ totalizando $150 \mathrm{~m}^{2}$ cada. As avaliações foram realizadas no período seco do ano e outra avaliação no período chuvoso. A área de SAF continha espécies frutíferas de ciclo curto, como a banana (Musa spp) e o mamão papaya (Carica papaya); espécies alimentares de subsistência, como o feijão (Phaseolus vulgaris L.), o milho (Zea mays), a mandioca (Manihot esculenta), as hortaliças e espécies de adubação verde, como a Leucena (Leucaena leucocephala) e a Gliricídia (Gliricidia sepium).

A caracterização da área estudo se dá na cidade de Cocal - PI, um município brasileiro do estado do Piauí, localizado na região de Parnaíba - PI, mesorregião do Norte piauiense e pertencente à região fisiográfica da caatinga. A cidade de Cocal - PI apresenta as seguintes coordenadas geográficas, Latitude: $3^{\circ} 28^{\prime} 16^{\prime \prime}$ Sul, Longitude: $41^{\circ} 33^{\prime} 18^{\prime \prime}$ Oeste e altitude de 160,0 metros. A temperatura média anual e a precipitação são $27,4^{\circ} \mathrm{C}$ e $900 \mathrm{~mm}$, respectivamente, com maior precipitação entre os meses de março a maio, quando excederem 

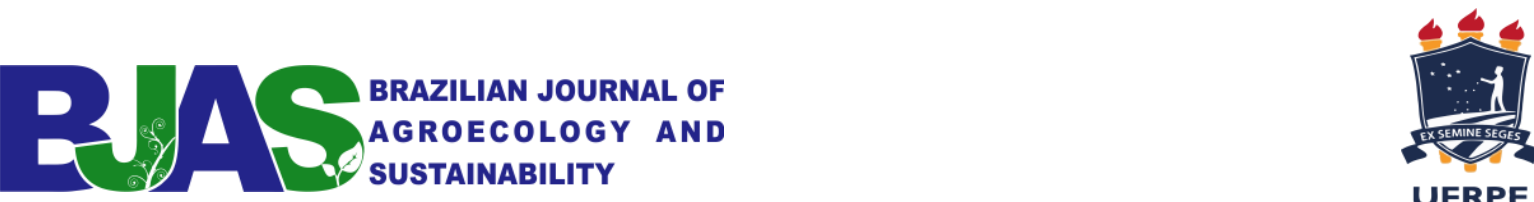

436,0 mm, e o mínimo de chuvas, com déficit de 728,0 mm, nos meses de julho a dezembro. O clima é tropical semiárido.

\subsection{Procedimentos metodológicos}

A pesquisa consistiu na quantificação da produção de serrapilheira acumulada sobre a superfície do solo, por meio da utilização de uma moldura de $0,5 \times 0,5 \mathrm{~m}$, lançada aleatoriamente em cada área demarcada (quatro subsistemas) e coletando-se o material orgânico existente sobre o solo e realizada mensalmente, visualizados na (Figura 1), totalizando assim, cinco amostragens em cada tratamento. A avaliação da produção e composição orgânica da serrapilheira acumulada sobre o solo do SAF e áreas de vegetação de caatinga foi realizada mensalmente ao longo do ano e considerado o período chuvoso e seco do ano.

Figura 1

Etapas de campo referentes às coletas de serrapilheira no campo (A e B)

A)

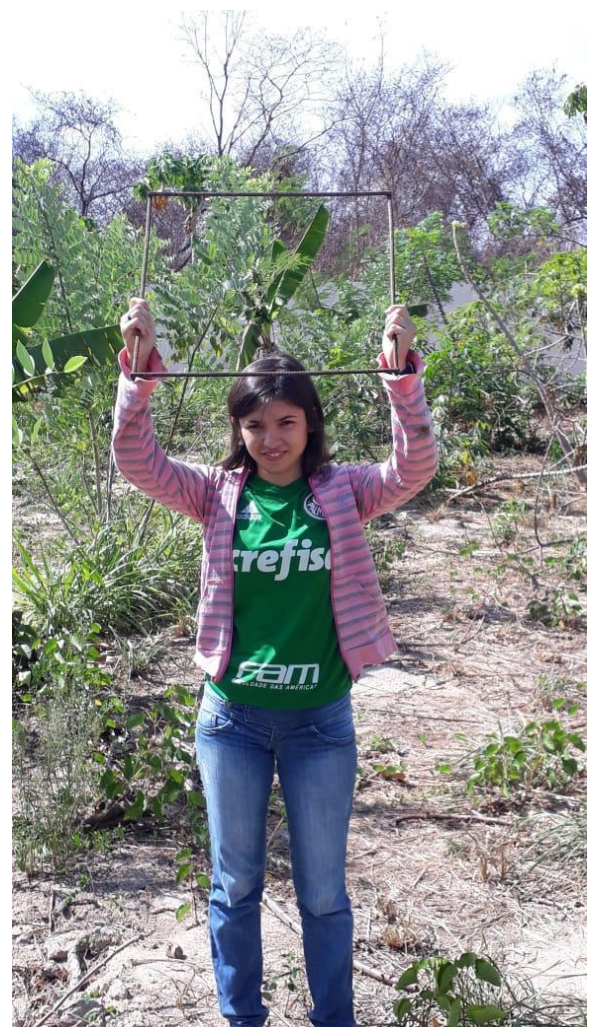

B)

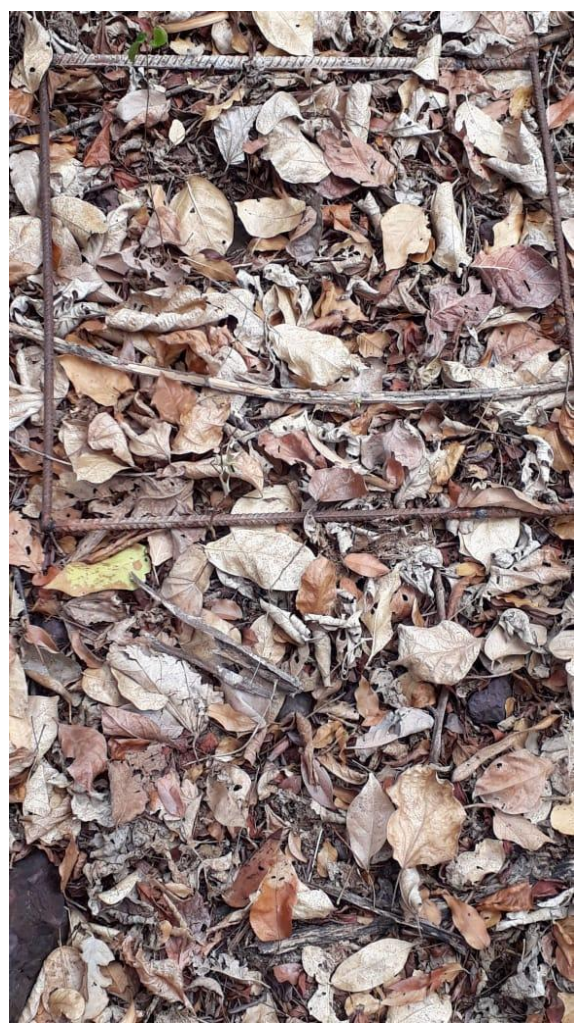

Fonte: Autor, 2018 
O material fresco coletado foi inicialmente acondicionado em sacos plásticos devidamente identificados e as amostras coletadas foram levadas ao Laboratório de agricultura/agroecologia do IFPI, campus Cocal, para pesagem e, posteriormente, secagem do material a temperatura de $65^{\circ} \mathrm{C}$ por 48 horas; e em seguida, foram descartados raízes finas, galhos e ramos maiores que $2 \mathrm{~cm}$ de diâmetro (Figura 2.). Posteriormente o processo de secagem, o material coletado foi separado manualmente nas frações folha, graveto lenhoso, graveto herbáceo, fruto/semente e miscelânea (material não identificado de origem animal ou vegetal) e em seguida pesado em balança de precisão, a fim de quantificar a biomassa seca. As amostras de serrapilheira foram pesadas para determinação da biomassa e logo após foram moídas para a análise orgânica (Empresa Brasileira de Pesquisa Agropecuária [EMBRAPA], 1997).

O processamento das amostras foi realizado no Laboratório de agricultura/agroecologia e as análises foram realizadas nas dependências do Laboratório de Bromatologia pertencente Universidade Estadual Vale do Acaraú - UVA.

\section{Figura 2}

Etapas de campo referentes às coletas de serrapilheira no campo e fracionamento dos extratos de serrapilheira $(A, B, C$ e $D)$

A)

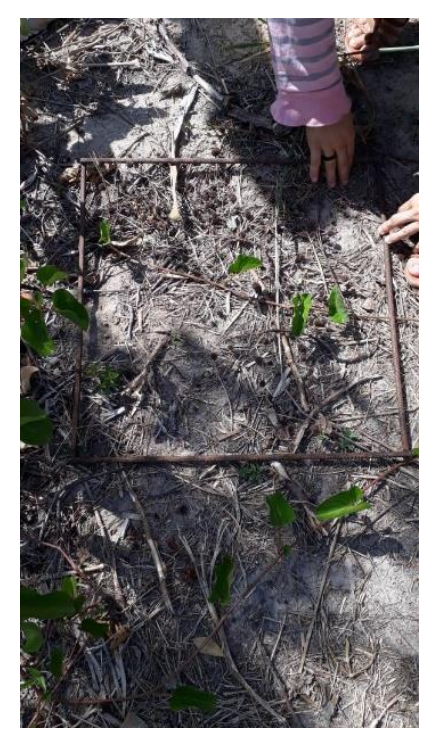

B)

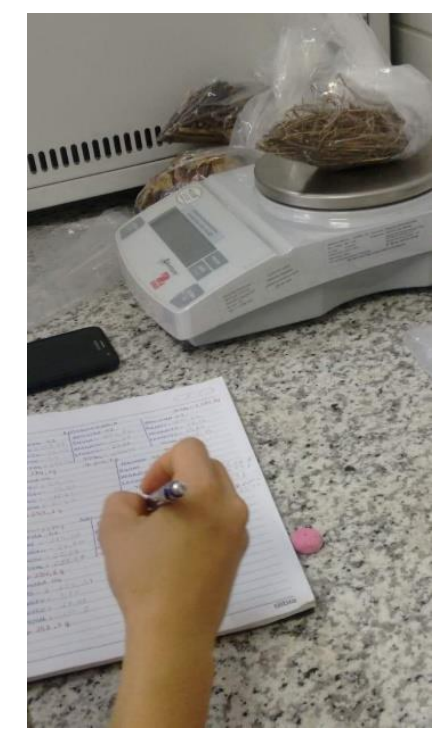


C)

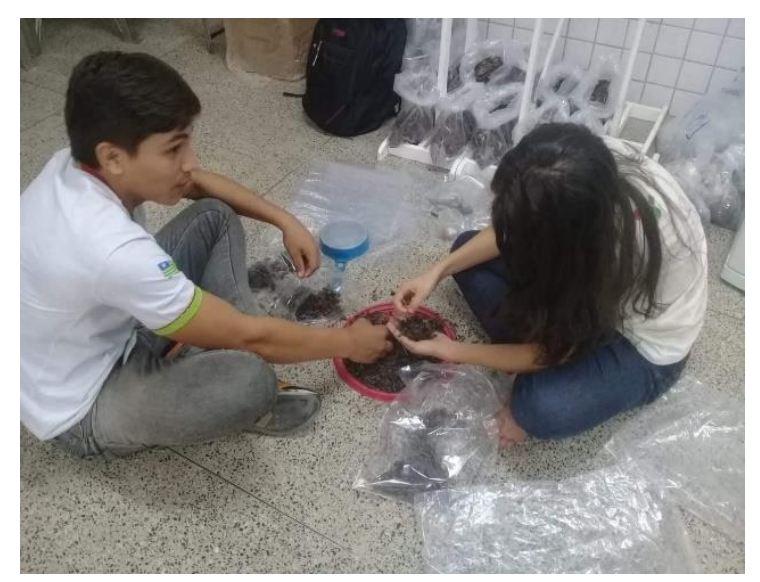

D)

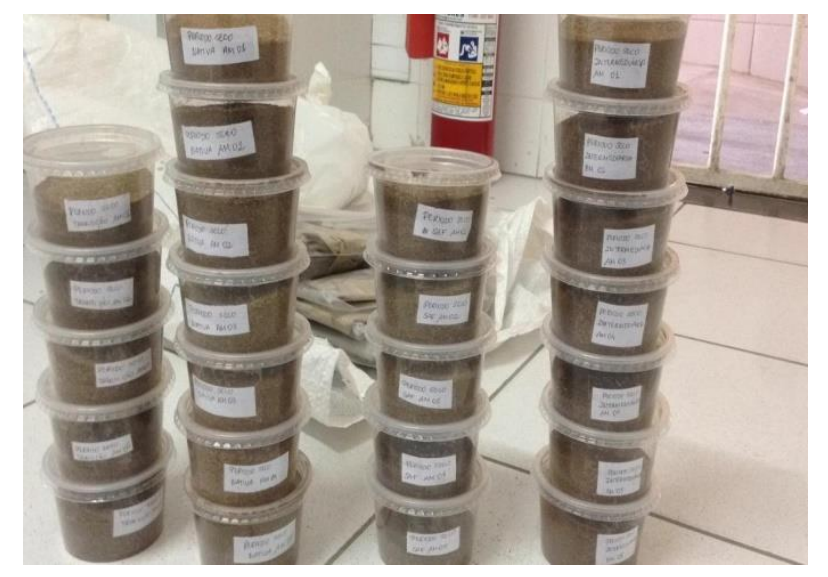

Fonte: Autor, 2018.

Para reduzir os problemas de contaminação do solo nas análises químicas durante a análise de matéria orgânica e minerais da manta/serrapilheira foi feito a separação desses materiais por peneiramento sequencial, com peneiras de $2 \mathrm{~mm}$ de malha. $\mathrm{O}$ material de solo que ficou retido nas peneiras foi descartado e depois foi determinado o conteúdo inorgânico e orgânico pela incineração da amostra em forno mufla a $600^{\circ} \mathrm{C}$. Todas as análises dos nutrientes seguiram as recomendações propostas por Detmann et al. (2012) e demonstrados na Figura 3.

A execução da pesquisa teve duração de 12 meses e seguiu o delineamento experimental que foi inteiramente casualizado em esquema fatorial $4 \times 2$ (quatro sistemas $\mathrm{x}$ dois períodos). O material coletado foi separado manualmente nos componentes: folha, graveto lenhoso e graveto herbáceo; e, em seguida, pesado em balança de precisão, a fim de quantificar a biomassa seca. As biomassas pré-secas foram utilizadas para estimativa das variáveis estudadas: biomassa de folhas verdes (BFV, $\mathrm{kg} \mathrm{ha}^{-1}$ ), biomassa de estrato lenhoso (BLEN; $\mathrm{kg} \mathrm{ha}^{-1}$ ), biomassa de estrato herbáceo (BHB; $\mathrm{kg} \mathrm{ha}^{-1}$ ), biomassa de forragem Total (BFT, $\mathrm{kg} \mathrm{ha}^{-1}$ ).

Foram avaliados os teores de matéria mineral da biomassa de folhas, gravetos lenhosos e do extrato herbáceo (MMFO, MMLEN e MMHB); e matéria orgânica da biomassa de folhas, gravetos lenhosos e do extrato herbáceo (MOF, MOLEN e MOHB).

As análises estatísticas foram realizadas utilizando o software SAS e as médias comparadas pelo teste de Tukey a 5\% de probabilidade (SAS Institute, 2003). 
Figura 3

Amostras de extratos de serrapilheira sendo analisadas (A e B)

A)

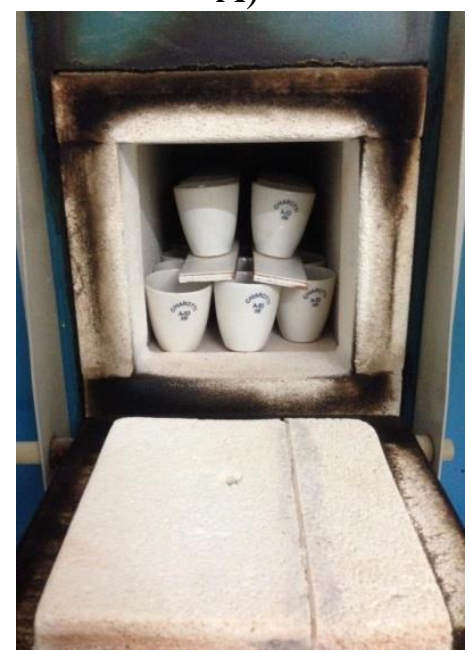

Fonte: Autor, 2018
B)

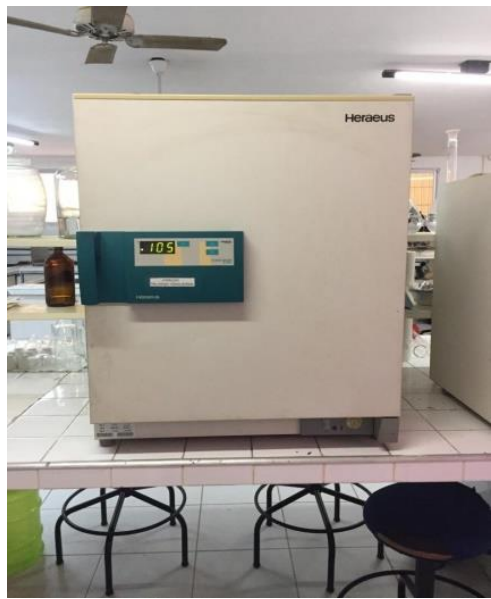

\section{RESULTADOS E DISCUSSÃO}

A avaliação da composição orgânica da serrapilheira nos diferentes sistemas de vegetação foi significativa (Tabela 1). Observou-se diferença significativa para o teor de matéria mineral da biomassa de folhas (MMFO) e no teor de matéria mineral da biomassa de gravetos lenhosos (MMLEN). Os teores de MMFO (41,35\%) e MMLEN (28,29\%) do SAF, bem como do sistema de Caatinga antropizada com valores de MMFO (35,24\%) e MMLEN (18,28\%), respectivamente, foram superiores aos demais sistemas avaliados, tal fato pode estar associado à atuação dos raios solares incidentes na camada de serrapilheira depositada sobre o solo e a maior umidade do solo durante a época chuvosa, favorecendo assim a mineralização conforme apresentado na Tabela 1. A produção de serapilheira é a devolução de nutrientes em ecossistemas florestais e se constituem a via mais importante de fluxo no sistema solo-plantasolo, do ciclo biogeoquímico de nutrientes (Villa et al., 2016). 
Tabela 1

Composição química da serrapilheira dos sistemas de vegetação da caatinga no município de Cocal - PI durante a época chuvosa do ano de 2018

\begin{tabular}{lccc}
\hline Sistemas & MMFO $^{1}$ & MMLEN $^{2}$ & MMHB $^{3}$ \\
\hline SAF & $41,35^{\mathrm{A}}$ & $28,29^{\mathrm{A}}$ & $14,35^{\mathrm{A}}$ \\
Caatinga Nativa & $19,21^{\mathrm{B}}$ & $4,53^{\mathrm{B}}$ & $7,30^{\mathrm{A}}$ \\
Caatinga Antropizada & $35,24^{\mathrm{A}}$ & $18,28^{\mathrm{A}}$ & $13,37^{\mathrm{A}}$ \\
Caatinga Degradada & $29,64^{\mathrm{A}}$ & $3,25^{\mathrm{B}}$ & $11,07^{\mathrm{A}}$ \\
\hline Sistemas & $\mathrm{MOF}^{4}$ & $\mathrm{MOLEN}^{5}$ & $\mathrm{MOHB}^{6}$ \\
\hline SAF & $68,52^{\mathrm{A}}$ & $83,00^{\mathrm{A}}$ & $72,94^{\mathrm{A}}$ \\
Caatinga Nativa & $80,76^{\mathrm{A}}$ & $93,48^{\mathrm{A}}$ & $93,38^{\mathrm{A}}$ \\
Caatinga Antropizada & $64,74^{\mathrm{A}}$ & $81,72^{\mathrm{A}}$ & $72,40^{\mathrm{A}}$ \\
Caatinga Degradada & $70,36^{\mathrm{A}}$ & $91,85^{\mathrm{A}}$ & $86,15^{\mathrm{A}}$
\end{tabular}

${ }^{1}$ Matéria mineral da biomassa de folhas (MMFO; \%); ${ }^{2}$ Matéria mineral do extrato lenhoso (MMLEN, \%); ${ }^{3}$ Matéria mineral do extrato herbáceo (MSHB, \%); ${ }^{4}$ Matéria orgânica das folhas (MOF; \%); ${ }^{5}$ Matéria orgânica do extrato lenhoso (MOLEN, \%); ${ }^{6}$ Matéria orgânica do extrato herbáceo (MOHB, \%). As letras indicam diferença estatística entre as médias comparadas pelo teste Tukey com $5 \%$ de probabilidade.

Fonte: Elaborada pelo autor, 2018.

Não foi observado efeito na matéria orgânica dos componentes da biomassa da serrapilheira de nenhum dos sistemas avaliados. Possivelmente, a densidade de árvores perenifólias e caducifólias dos sistemas avaliados foi suficiente para permitir um maior aporte de matéria orgânica no solo ao longo do tempo estudado no presente trabalho. Nesse contexto, pode-se atestar que a Caatinga Antropizada e o Sistema Agroflorestal apresentaram-se como satisfatórios, com aumento na taxa de decomposição da serapilheira conforme Tabela 1.

Ressalta-se que o processo de reciclagem dos nutrientes possui sua dinâmica regulada diretamente pelo material orgânico dispersado pelas árvores e da decomposição da biomassa morta nos solos (Ourique et al., 2016), influenciando na quantidade e qualidade da serrapilheira depositada, que, por sua vez, é determinada pela quantidade de compostos orgânicos e inorgânicos (frações solúveis, nutrientes, lignina, celulose, compostos fenólicos, carbono, substâncias estimulantes ou alelopáticas) que exercem grande influência sobre as interações da fauna do solo e, consequentemente, na decomposição (Pinto et al., 2016).

Verifica-se que na época das águas, os sistemas de Caatinga Nativa $\left(5.595,20 \mathrm{~kg} \mathrm{ha}^{-1}\right) \mathrm{e}$ a Caatinga Antropizada (7.483,00 $\left.\mathrm{kg} \mathrm{ha}^{-1}\right)$ apresentaram a maior deposição de serrapilheira (Figura 4). Esse resultado está associado a maior deposição de plantas do estrato herbáceo logo após as primeiras chuvas, plantas que são de ciclos curtos, onde uma pequena quantidade de 

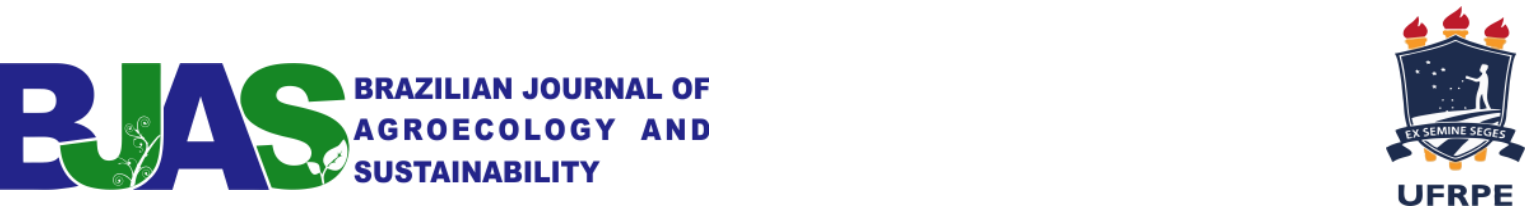

água é suficiente para que estas possam rebrotar, constituindo adaptações genéticas destas espécies às vegetações do semiárido.

$\mathrm{Na}$ época seca os sistemas SAF (7.658,1 $\left.\mathrm{kg} \mathrm{ha}^{-1}\right)$ e a Caatinga Nativa $\left(7.041,0 \mathrm{~kg} \mathrm{ha}^{-1}\right)$ obtiveram maiores resultados (Figura 4), tal fato está associado à diminuição do conteúdo de água do solo durante a época seca. Essa resposta já foi observada em outros trabalhos para a biomassa de forragem total (Henriques et al., 2016; Ferreira et al., 2014), já que a quase totalidade das espécies da Caatinga apresentam aspecto caducifólio, portanto perdem as folhas na época seca do ano. Na época seca ocorre a maior deposição de plantas do estrato herbáceo, principalmente no SAFs, devido à presença de palhadas de culturas de subsistência, como o feijão, o milho, a mandioca e as hortaliças.

Figura 4

Produção de biomassa de Serrapilheira em diferentes sistemas de Caatinga e sistema Agroflorestal

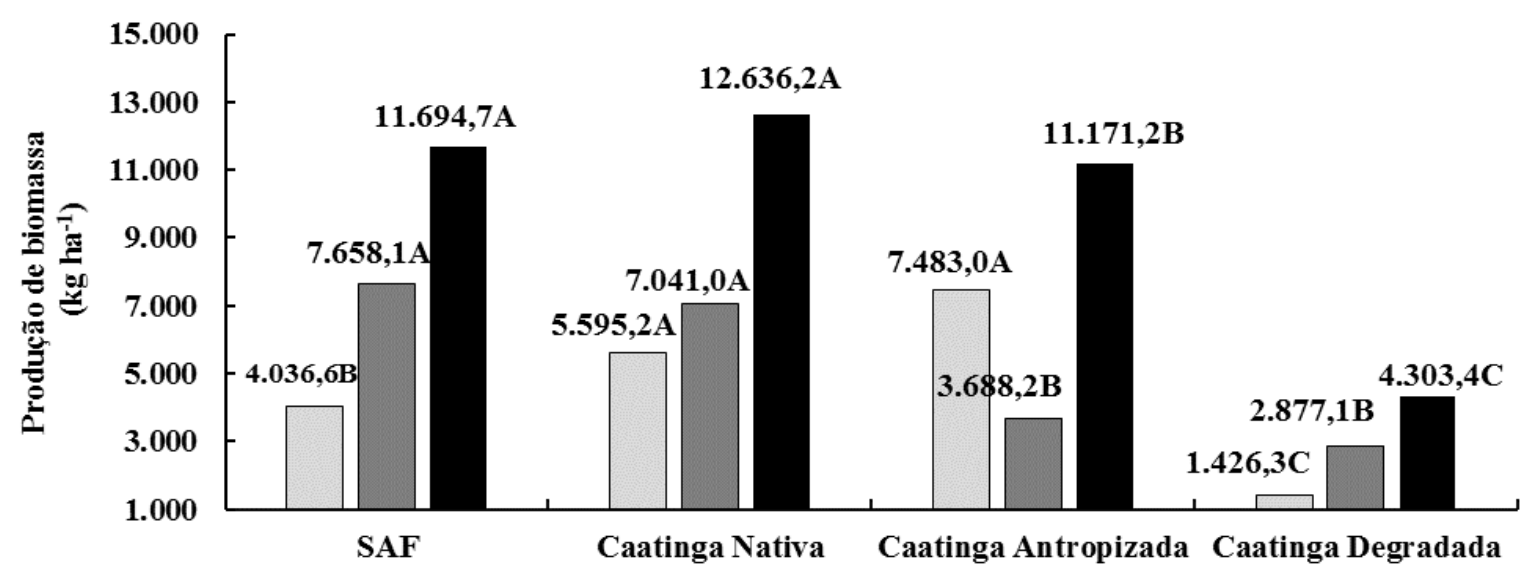

Sistemas de vegetação

$\square \quad$ BFT (Época das águas) $\square$ BFT (Época seca) $\square$ BFT (Anual)

*Biomassa de Forragem Total (BFT; $\mathrm{kg} \mathrm{ha}^{-1}$ ). As letras indicam diferença estatística entre as médias comparadas pelo teste Tukey com $5 \%$ de probabilidade.

Fonte: Elaborada pelo autor, 2018.

O sistema Caatinga Degradada apresentou baixa produção de serrapilheira para época das águas $\left(1.426,30 \mathrm{~kg} \mathrm{ha}^{-1}\right)$, assim como na época seca $\left(2.877,10 \mathrm{~kg} \mathrm{ha}^{-1}\right)$. Essa resposta resulta da ação humana, sem realização de manejo da caatinga de maneira a favorecer a deposição de serrapilheira, o que proporcionou uma redução da biomassa de plantas importantes do bioma, permitindo a erosão e a exposição do solo, acarretando em estágios sucessivos de degradação. 

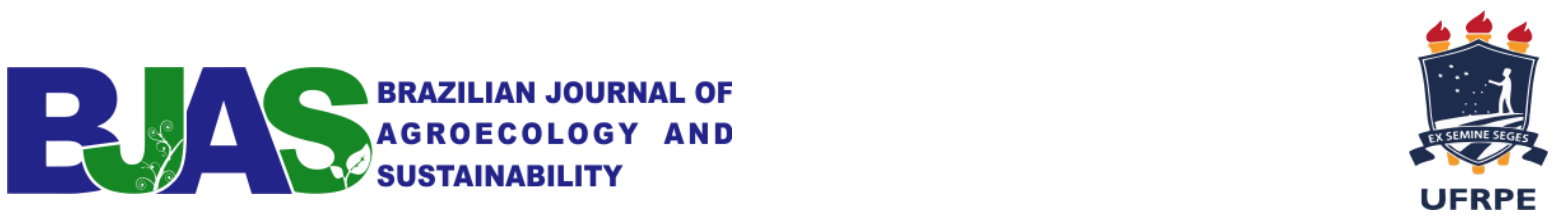

Vale ressaltar, que estes resultados atestam que a falta de manejo adequado leva ao esgotamento do solo, bem como ao desmatamento de novas áreas no intuito de buscar novas fontes de alimento para os animais durante todo o ano, mas principalmente na época seca.

É oportuno destacar que as ponderações de Henriques et al. (2016), quanto a sazonalidade das variações na deposição da fração de folhas nas áreas de vegetação da caatinga, permitem aos estudiosos inferir como a vegetação responde às variações climáticas, à distribuição e estoque dos nutrientes contidos na serrapilheira acumulada, além de dar suporte para se entender as estratégias usadas pela vegetação na manutenção da sustentabilidade do ecossistema. Os resultados são similares a atual pesquisa e, nesse contexto, as plantas de médio porte, com características arbóreo-arbustivas, folhas pequenas modificadas em espinhos, estão adaptadas às condições climáticas do semiárido.

Além disso, há acentuada caducifólia onde as plantas perdem suas folhas durante os longos meses de estiagem anual na Caatinga (Amorim et al., 2014; Henriques et al., 2016). As informações corroboram com os resultados obtidos por Diogo et al. (2014), que ao estudarem a produção de serrapilheira, obtiveram um total estimado de $2.731,6 \mathrm{~kg} \mathrm{ha}^{-1}$ ano $^{-1}$; e no trabalho de Silva et al. (2015) que obtiveram produção de serrapilheira de $1.630,5 \mathrm{~kg} \mathrm{ha}^{-1}$ ano ${ }^{-1}$.

A deposição da serrapilheira corresponde a uma das etapas mais importantes da ciclagem de nutrientes em um bioma, seu acúmulo na superfície do solo é regulado pela quantidade de material (folhas, galhos, flores, cascas e demais partes das plantas) e pela sua taxa de decomposição (Andrade \& Amorim, 2018; Amorim et al., 2014). Observando a Figura 5, verifica-se que na Caatinga Nativa (5.256,30 $\left.\mathrm{kg} \mathrm{ha}^{-1}\right)$ e na Caatinga Antropizada (7.176,80 $\mathrm{kg} \mathrm{ha}^{-1}$ ) a deposição de serrapilheira ocorreu em maior quantidade no componente biomassa de folha verde (BFV) (Figura 5), tal resultado está associado à diminuição do conteúdo de água do solo durante a época seca. Costa et al. (2010) afirmaram que esse comportamento é uma medida preventiva à alta perda de água por transpiração foliar. Isso explica porque há uma maior produção de BFV nestes sistemas.

Esse comportamento era esperado para a biomassa de forragem verde, já que a quase totalidade das espécies da Caatinga apresentam aspecto caducifólio, portanto perdem as folhas na época seca do ano. A fração folha destacou-se sendo responsável por 94\% e $79 \%$ da produção total de serrapilheira da área estudada, para os sistemas de Caatinga Nativa e Caatinga Antropizada, respectivamente. Esta fração é relevante do ponto de vista pastoril, uma vez que compõe parte da dieta de pequenos ruminantes principalmente na época seca do ano, quando a disponibilidade de biomassa de forragem verde é bastante reduzida. 
Figura 5

Produção de serrapilheira em áreas diferentes de caatinga e em sistema agroflorestal durante a época seca de 2018

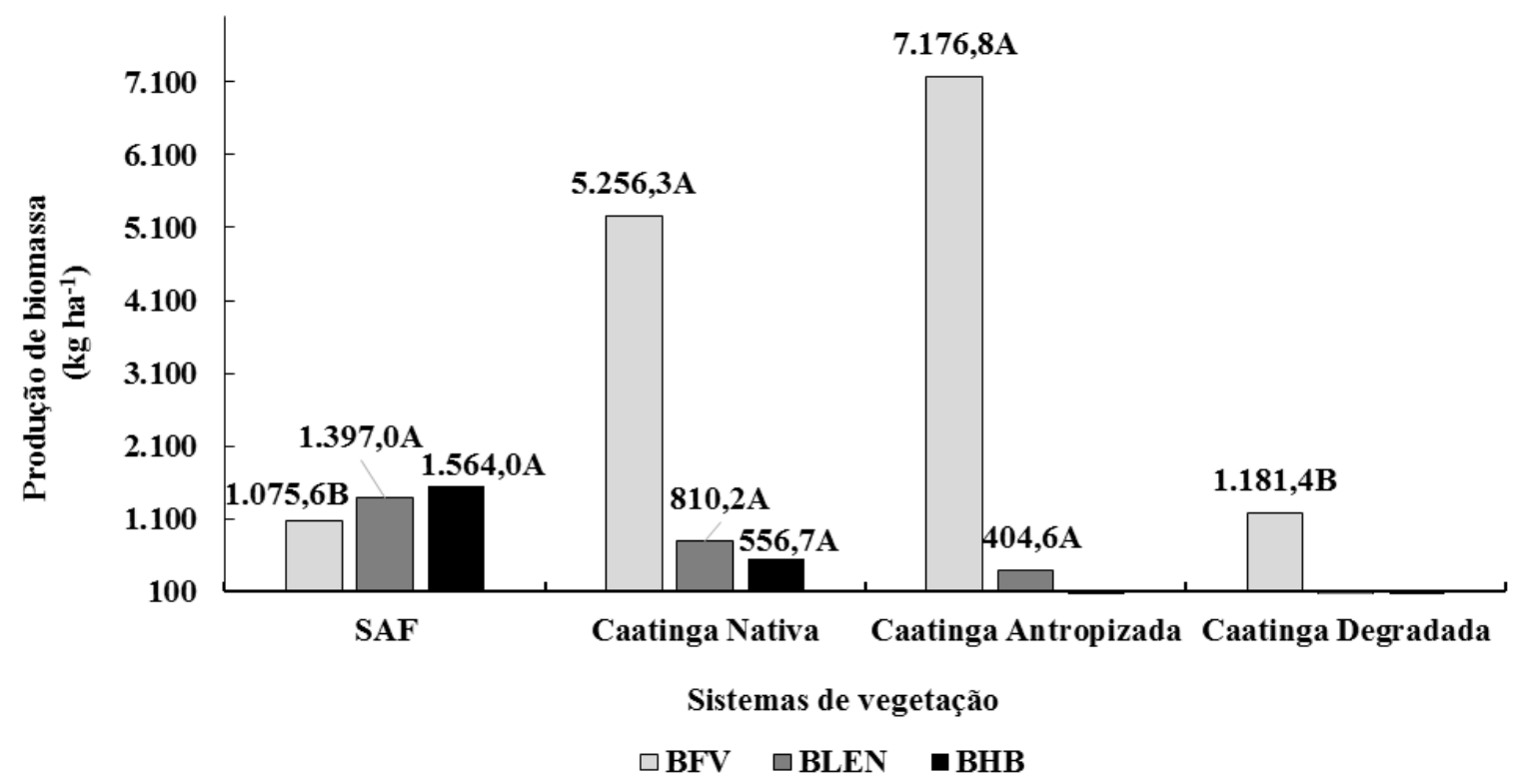

*Biomassa de folha verde (BFV; $\mathrm{kg} \mathrm{ha}^{-1}$ ); biomassa de estrato lenhoso (BLEN; $\mathrm{kg} \mathrm{ha}^{-1}$ ); biomassa de estrato herbáceo $\left(\mathrm{BHB} ; \mathrm{kg} \mathrm{ha}^{-1}\right)$. As letras indicam diferença estatística entre as médias comparadas pelo teste Tukey com $5 \%$ de probabilidade.

Fonte: Elaborada pelo autor, 2018.

O sistema agroflorestal apresentou a maior BLEN $\left(1.397,05 \mathrm{~kg} \mathrm{ha}^{-1}\right)$, tal fato deve-se a maior presença de plantas leguminosas, de crescimento arbustivo e arbóreo, como a Leucena e a Gliricídia. O SAF também apresentou maior BHB $\left(1.563,96 \mathrm{~kg} \mathrm{ha}^{-1}\right)$, podendo tal resultado ser explicado dado a presença de espécies alimentares de subsistência, como o feijão, o milho, a mandioca e as hortaliças.

O sistema Caatinga Degradada apresentou apenas a BFV (1.181,37 $\left.\mathrm{kg} \mathrm{ha}^{-1}\right)$, essa resposta resulta da ação humana, sem realização de manejo da caatinga de maneira a favorecer a sua produção total, o que proporcionou uma redução da biomassa de plantas importantes do bioma, levando a estágios sucessivos de degradação no ecossistema.

A realização de pesquisas quanto à deposição de serrapilheira em área de vegetação da Caatinga é uma atividade complexa em virtude de inúmeros fatores climáticos, florísticos, fitossociológicos e fisiológicos (White et al., 2013). Na pesquisa realizada por Silva et al. (2012), com o objetivo de avaliar o efeito de dois tipos de manejo agroflorestal em SAFs sobre os estoques de serrapilheira, foram obtidos antes da poda uma produção de $442,40 \mathrm{~g} \mathrm{~kg}^{-1} \mathrm{e}$ $290,26 \mathrm{~g} \mathrm{~kg}^{-1}$ de serrapilheira, respectivamente. Esses resultados foram semelhantes aos obtidos nessa pesquisa quando comparados com a área de SAF, houve incremento na deposição de 

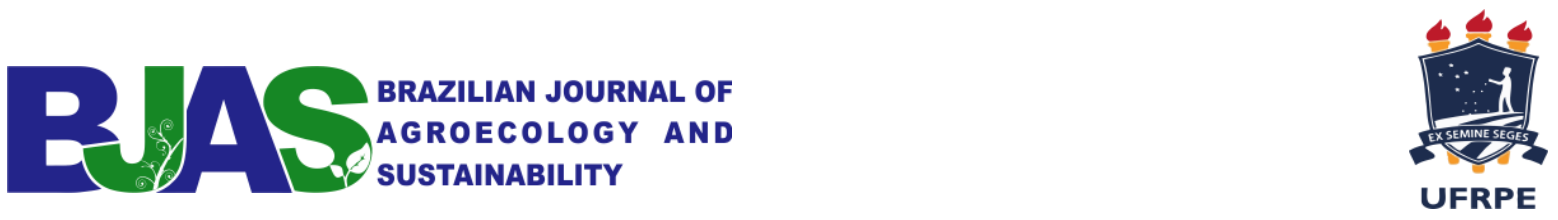

serrapilheira de $190 \%$ de matéria orgânica (MO) na serrapilheira em comparação ao manejo antes da poda, a saber, $290,26 \mathrm{~g} \mathrm{~kg}^{-1}$ vs $842,88 \mathrm{~g} \mathrm{~kg}^{-1}$, respectivamente.

Ressalta-se que, a serrapilheira promove benefícios ao solo, mantendo a sua estrutura e reduzindo a temperatura do mesmo, bem como protege o solo da erosão (Pimenta et al., 2011), de maneira que a deposição de serapilheira é influenciada por diversos fatores, como precipitação, temperatura, vento, conteúdo de água disponível no solo, umidade do ar, por exemplo, tornando-se difícil quantificar a contribuição desses fatores de forma isolada, e, principalmente, correlacioná-los com a produção de serapilheira (Silva et al., 2016).

No tocante à vegetação de Caatinga Nativa, os valores obtidos nesse estudo foram semelhantes aos obtidos por Mourão (2013) que ao trabalhar com a avaliação de serrapilheira em área de Caatinga Nativa apresentou distribuição sazonal da serrapilheira, obtendo um pico de produção de serrapilheira de 5.524,98 $\mathrm{kg} \mathrm{ha}^{-1}$ no primeiro trimestre (Jan-Mar); e reduzindo no terceiro trimestre (Jul-Set) a aproximadamente $3.600 \mathrm{~kg} \mathrm{ha}^{-1}$.

\section{CONSIDERAÇÕES FINAIS}

A decomposição da serrapilheira é incrementada nas áreas de Caatinga Antropizada e no Sistema Agroflorestal. Ao que diz respeito à Caatinga Nativa e ao Sistema Agroflorestal, esses são promissores para a criação animal no semiárido. Já a fração folha foi a que contribuiu com maior percentual na composição da serrapilheira em todos os sistemas estudados.

\section{REFERÊNCIAS}

Andrade, F. A. F., \& Amorim, L. B. (2018). Deposição, estoque e decomposição de serapilheira em ecótono caatinga - cerrado em Oeiras, PI. Revista Somma, Teresina, 4(2), 102-114.

Amorim, L. B., Salcedo, I. H., Pareyn, F. G. C., \& Alvarez, I. A. (2014). Assessment of nutrient returns in a tropical dry forest after clear-cut without burning. Nutrient Cycling Agroecosystems, 100(3), 333-343.

Araujo Filho, J. A. de. (2013). Manejo pastoril sustentável da caatinga. Recife: Projeto Dom Helder Câmara.

Corrêa Neto, T. A., Anjos, L. H. C., Pereira, M. G., \& Jaccoud, C. F. S. (2014). Aporte de serapilheira em plantios de eucalipto em função da qualidade do sítio. Pesquisa Florestal Brasileira, Colombo, 34(80), 399-406.

Costa, C. C. A., Camacho, R. G. V., Macedo, I. D., \& Silva, P. C. M. (2010). Análise comparativa da produção de serrapilheira em fragmentos arbóreos e arbustivos em área de Caatinga na FLONA de Açu-RN. Revista Árvore, 34(2), 259-265. 

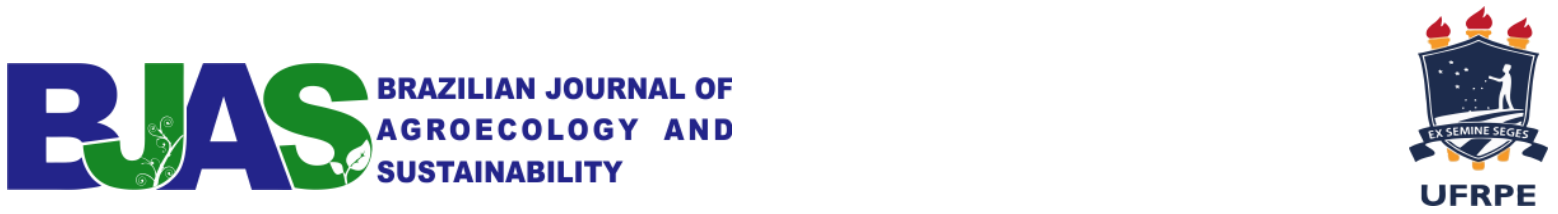

Detmann, E., Souza, M. A., \& Valadares Filho, S. C. (2012). Métodos para análise de alimentos (214 p.). Viçosa, MG: Suprema.

Diogo, I. J. S., Vieira, I. R, Silveira, A. P, \& Araújo, F. S. (2014). The influence of abiotic factors on litter deposition in a semiarid area, northeastern Brazil. Revista do Instituto Florestal, São Paulo, 26(2) 203-213.

Ferreira, C. D., Souto, P. C., Lucena, D. S., Sales, F. C. V., \& Souto, J. S. (2014). Florística do banco de sementes no solo em diferentes estágios de regeneração natural de Caatinga. Revista Brasileira de Ciências Agrárias, 9(4), 562-569.

Henriques, Í. G. N., Souto, J. S., Souto, P. C., Santos, W. S., Henriques, I. G. N., \& Lima, T. S. (2016). Acúmulo, deposição e decomposição de serrapilheira sob a dinâmica vegetacional da Caatinga em Unidade de Conservação. Revista Verde de Agroecologia e Desenvolvimento Sustentável, 11(1), 84-89.

Holanda, A. C., Feliciano, A. L. P., Freire, F. J., Sousa, F. Q., Freire, S. R. O., \& Alves, A. R. (2017). Aporte de serapilheira e nutrientes em uma área de caatinga. Ciência Florestal, 27(2), 621-633.

Mourão, A. E. B. (2013). Parâmetros florísticos, fitossociológicos e de produção de biomassa para orçamentação forrageira participativa em áreas de caatinga no assentamento Vista Alegre, Quixeramobim, Ceará: um estudo de caso. Dissertação (Mestrado em Zootecnia), Universidade Estadual Vale do Acaraú - UVA, Sobral, Ceará, Brasil.

Ourique, L. K., Silva, R. O., Souza, C. A. S., Noguchi, H., Santos, J., \& Higuchi, N. (2016). Relação da produção de serapilheira com incremento em diâmetro de uma floresta madura na Amazônia Central. Scientia Forestalis, 44(112), 875-886.

Pimenta, J. A., Rossi, L. B., Torezan, J. M. D., Cavalheiro, A. L. \& Bianchini, E. (2011). Produção de serrapilheira e ciclagem de nutrientes de um reflorestamento e de uma floresta estacional semidecidual no sul do Brasil. Acta Botanica Brasilica, 25(1), 53-57.

Pinto, M. N., Lima, R. A., \& Meira-Neto, J. A. (2020). Ecologia funcional: Relação do gradiente pedológico e abundância de espécies lenhosas do Cerrado Brasileiro. Biota Amazônia, 10(1), 6-10.

Statistical Analysis System. (2003). User's Guide (129 p.). Cary, NC: SAS Institute Inc.

Silva, W. T. M., Leonardo, F. A. P., Souto, J. S., Souto, P. C., Lucena, J. D. S., \& Medeiros Neto, P. H. (2016). Deposição de serapilheira em áreas de Caatinga no Núcleo de Desertificação do Seridó. Agropecuária Científica no Semiárido, 12(4), 383-390.

Silva, V. N., Souto, L. S., Dutra Filho, J. A., Souza, T. M. A., \& Borges, C. H. A. (2015). Deposição de serapilheira em uma área de caatinga preservada no semiárido da Paraíba, Brasil. Revista Verde de Agroecologia e Desenvolvimento Sustentável, Pombal, 10(2), $21-25$. 

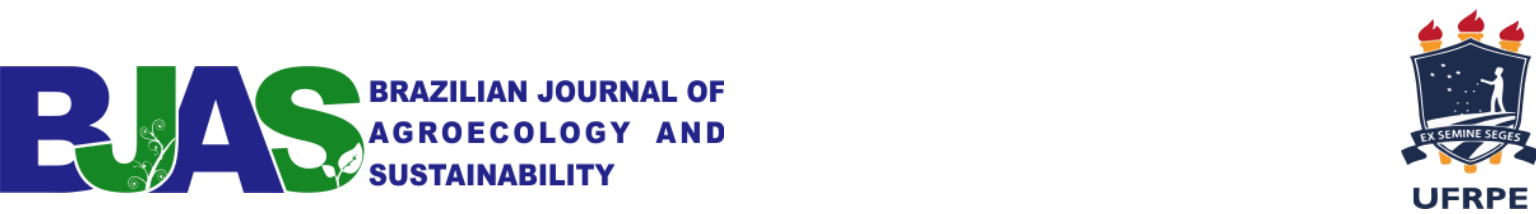

Silva, M. S. C., Silva, E. M. R., Pereira, M. G., \& Silva, C. F. Estoque de serapilheira e atividade microbiana em solo sob sistemas agroflorestais (2012). Floresta e Ambiente. 19(4),431441.

Souto, P. C., Souto, J. S., Santos, R. V., Bakke, I. A., Sales, F. C. V., \& Souza, B. V. (2013). Taxa de decomposição da serrapilheira e atividade microbiana em área de Caatinga. Cerne, 19(4), 559-565.

Villa, E. B., Pereira, M. G., Alonso, J. M., Beutler, S. J., \& Leles, P. S. D. S. (2016). Aporte de serapilheira e nutrientes em área de restauração florestal com diferentes espaçamentos de plantio. Floresta e Ambiente, 23(1), 90-99.

White, B. L. A., Nascimento, D. L., Dantas, T. V. P. \&, Ribeiro, A. S. (2013). Dynamics of the production and decomposition of litterfall in a brazilian northeastern tropical forest Serra de Itabaiana National Park, Sergipe State. Acta Scientiarum, (35), 195-201.

\section{AGRADECIMENTOS}

Os autores agradecem à Fundação de Amparo à Pesquisa no Piauí- FAPEPI, ao

Conselho Nacional de Desenvolvimento Científico e Tecnológico - CNPq pelo apoio financeiro e tecnológico na execução do estudo e ao Instituto Federal de Educação, Ciência e Tecnologia do Piauí - IFPI Campus Cocal. 